\title{
Costs and Consequences Associated With Misdiagnosed Lower Extremity Cellulitis
}

\section{Citation}

Weng, Qing Yu, Adam B. Raff, Jeffrey M. Cohen, Nicole Gunasekera, Jean-Phillip Okhovat, Priyanka Vedak, Cara Joyce, Daniela Kroshinsky, and Arash Mostaghimi. 2017. "Costs and Consequences Associated With Misdiagnosed Lower Extremity Cellulitis." JAMA Dermatology 153 (2) (February 1): 141. doi:10.1001/jamadermatol.2016.3816.

\section{Published Version}

doi:10.1001/jamadermatol.2016.3816

\section{Permanent link}

http://nrs.harvard.edu/urn-3:HUL.InstRepos:33785925

\section{Terms of Use}

This article was downloaded from Harvard University's DASH repository, and is made available under the terms and conditions applicable to Other Posted Material, as set forth at http:// nrs.harvard.edu/urn-3:HUL.InstRepos:dash.current.terms-of-use\#LAA

\section{Share Your Story}

The Harvard community has made this article openly available.

Please share how this access benefits you. Submit a story.

\section{Accessibility}




\section{Costs and Consequences Associated With Misdiagnosed Lower Extremity Cellulitis}

Qing Yu Weng, MD; Adam B. Raff, MD, PhD; Jeffrey M. Cohen, MD; Nicole Gunasekera, BS; Jean-Phillip Okhovat, MD, MPH; Priyanka Vedak, MD; Cara Joyce, PhD; Daniela Kroshinsky, MD, MPH; Arash Mostaghimi, MD, MPA, MPH

IMPORTANCE Inflammatory dermatoses of the lower extremity are often misdiagnosed as cellulitis (aka "pseudocellulitis") and treated with antibiotics and/or hospitalization. There is limited data on the cost and complications from misdiagnosed cellulitis.

OBJECTIVE To characterize the national health care burden of misdiagnosed cellulitis in patients admitted for treatment of lower extremity cellulitis.

DESIGN, SETTING, AND PARTICIPANTS Cross-sectional study using patients admitted from the emergency department (ED) of a large urban hospital with a diagnosis of lower extremity cellulitis between June 2010 and December 2012. Patients who were discharged with a diagnosis of cellulitis were categorized as having cellulitis, while those who were given an alternative diagnosis during the hospital course, on discharge, or within 30 days of discharge were considered to have pseudocellulitis. A literature review was conducted for calculation of large-scale costs and complication rates. We obtained national cost figures from the Medical Expenditure Panel Survey (MEPS), provided by the Agency for Healthcare Research and Quality (AHRQ) for 2010 to calculate the hospitalization costs per year attributed to misdiagnosed lower extremity pseudocellulitis.

EXPOSURES The exposed group was composed of patients who presented to and were admitted from the ED with a diagnosis of lower extremity cellulitis.

MAIN OUTCOMES AND MEASURES Patient characteristics, hospital course, and complications during and after hospitalization were reviewed for each patient, and estimates of annual costs of misdiagnosed cellulitis in the United States.

RESULTS Of 259 patients, 79 (30.5\%) were misdiagnosed with cellulitis, and 52 of these misdiagnosed patients were admitted primarily for the treatment of cellulitis. Forty-four of the 52 (84.6\%) did not require hospitalization based on ultimate diagnosis, and 48 (92.3\%) received unnecessary antibiotics. We estimate cellulitis misdiagnosis leads to 50000 to 130000 unnecessary hospitalizations and $\$ 195$ million to $\$ 515$ million in avoidable health care spending. Unnecessary antibiotics and hospitalization for misdiagnosed cellulitis are projected to cause more than 9000 nosocomial infections, 1000 to 5000 Clostridium difficile infections, and 2 to 6 cases of anaphylaxis annually.

CONCLUSIONS AND RELEVANCE Misdiagnosis of lower extremity cellulitis is common and may lead to unnecessary patient morbidity and considerable health care spending.
Editorial page 134

Supplemental content

Related article at jama.com
Author Affiliations: Dept of Dermatology, Massachusetts General Hospital, Boston (Weng, Raff, Vedak, Kroshinsky); Dept of Dermatology, Brigham and Women's Hospital Boston, Massachusetts (Cohen, Gunasekera, Okhovat, Mostaghimi); Dept of Biostatistics and

Bioinformatics, Tulane School of Public Health and Tropical Medicine New Orleans, Louisiana (Joyce).

Corresponding Author: Arash Mostaghimi, MD, MPA, MPH, Department of Dermatology, Department of Medicine, Brigham and Women's Hospital, Harvard Medical School, 15 Francis St PBB-B 421, Boston, MA 02115 (amostaghimi@bwh.harvard.edu). 
ellulitis is a common bacterial skin infection that leads to 2.3 million emergency department (ED) visits annually in the United States. ${ }^{1}$ Between $13.9 \%$ and $17 \%{ }^{1-3}$ of patients seen in the ED with cellulitis are admitted, accounting for $10 \%$ of all infectious disease-related US hospitalizations. ${ }^{4}$ Cellulitis ambulatory care costs in the United States in 2006 were $\$ 3.7$ billion, ${ }^{5}$ a cost that continues to rise as ambulatory visits and inpatient admissions increase. ${ }^{6,7}$

Patients with cellulitis present with erythema, edema, warmth, and tenderness of the skin. Fever and leukocytosis may also be present but are not required for diagnosis. ${ }^{8,9}$ The clinical course of cellulitis is typically characterized by acute onset and rapid response to antibiotics. The lower extremity is involved in $70 \%$ to $80 \%$ of patients, ${ }^{10}$ although any area of skin may be affected. In cases involving the extremities, cellulitis usually presents unilaterally. ${ }^{11}$ Objective diagnostic modalities for cellulitis, such as blood and skin cultures (including needle aspiration and biopsies) are rarely revealing ${ }^{12,13}$ and diagnosis is usually made by medical history and physical examination alone.

Many inflammatory dermatoses of the skin clinically mimic cellulitis (aka pseudocellulitis), leading to a misdiagnosis rate of $30 \%$ to $90 \% .^{14-16}$ Common mimickers of cellulitis include venous stasis dermatitis, lymphedema, deep venous thrombosis, gout, and contact dermatitis. ${ }^{17}$ Patients with presumed cellulitis are routinely given empirical antibiotics and many are hospitalized, leading to potential waste and unnecessary exposure to antibiotics for those misdiagnosed. ${ }^{17}$

There is limited data on the economic cost, complications, and unnecessary utilization rates associated with misdiagnosed cellulitis. We sought to determine the health care burden of misdiagnosed cellulitis in patients who were admitted from the ED to the hospital for treatment of lower extremity cellulitis.

\section{Methods}

\section{Case Identification and Data Collection}

We performed a retrospective cross-sectional study of all patients presenting to and admitted from the ED of a large urban hospital with a diagnosis of lower extremity cellulitis between June 2010 and December 2012. Patients were identified using the Research Patient Data Repository (RPDR), a clinical data registry of all patients within the Partners Healthcare System. Information stored in the RPDR includes patient demographics, medications, laboratory reports, and visit notes. We queried the RPDR using ICD9 codes for lower extremity cellulitis $(681.10,682.6,682.7,682.8,682.9)$, location of service (ED), and age ( $\geq 18$ years) to identify eligible patients.

Patients 18 years or older who were diagnosed with cellulitis by the ED physician or admitting team, presented directly to the ED, and were subsequently admitted were eligible for inclusion in the study. Exclusion criteria included non-lower extremity cellulitis, intravenous antibiotics within the 48 hours prior to presentation, surgery within the prior 30 days, abscess, penetrating trauma, burn, known osteomyelitis, diabetic ulcer, or indwelling hardware at site. Patients who were

\section{Key Points}

Question What is the national health care burden of misdiagnosed lower extremity cellulitis in patients admitted to the hospital from the emergency department?

Findings In this cross-sectional study that included 259 patients, $30 \%$ were misdiagnosed with cellulitis, of which $85 \%$ did not require hospitalization and $92 \%$ received unnecessary antibiotics. Combining these findings with previously published data, cost estimates, and and projections indicate that cellulitis misdiagnosis leads to 50000 to 130000 unnecessary hospitalizations in the United States and $\$ 195$ million to $\$ 515$ million in avoidable health care spending annually.

Meaning Misdiagnosis of lower extremity cellulitis is common and may lead to unnecessary patient morbidity and considerable health care spending.

discharged with a diagnosis of cellulitis were categorized as having cellulitis, whereas those who were given an alternative diagnosis during the hospital course, on discharge, or within 30 days of discharge were considered to have pseudocellulitis. For diagnoses that were changed within 30 days, only those that specifically changed the diagnosis of the initial cellulitis hospitalization were considered. Some medical charts used the term "erysipelas," which was considered a subtype of cellulitis in this study and therefore included as a cellulitis diagnosis.

Each patient medical record was individually reviewed to document medical history, presentation, and hospital course for their admission. Following discharge, the postdischarge course over 30 days was evaluated, and variables collected included presence and type of complications (eg, rash, anaphylaxis, gastrointestinal distress, diarrhea, Clostridium difficile infection, infusion reaction, peripherally inserted central catheter placement thrombosis and /or infection, or hematologic abnormality), representation to the ED or outpatient clinic, and readmission. Outpatient, ED, and hospital visits for routine follow-up or issues unrelated to the misdiagnosis were not collected.

A formal medical record review protocol was developed, and eligible patients were selected per the inclusion and exclusion criteria described above (Figure). Data were recorded using Research Electronic Data Capture (version 6, REDCap). ${ }^{18}$ Each reviewer was trained by A.R. and Q.Y.W. during a training period in which medical records were reviewed together. All conflicting and ambiguous elements were noted and subsequently discussed among all authors until a unanimous decision was reached. A subset of medical records was also reviewed by multiple reviewers to establish interreviewer consistency.

When evaluating the necessity of antibiotic use or admission for patients whose cellulitis diagnosis was ultimately changed, determination of proper treatment was reviewed by 2 board-certified dermatologists (D.K. and A.M.). Diagnoses that were considered appropriate for admission were morbid, requiring treatments or evaluations that needed to be treated in a hospital setting (eg, congestive heart failure requiring intravenous diuretics, calciphylaxis requiring pain control, or critical limb ischemia), while those considered appropriate for antibiotics were any condition with a bacterial 
etiology (eg, osteomyelitis, septic bursitis). Any difference between dermatologists on treatment was decided by consensus. Partners Healthcare Institutional Review Board approval was obtained for this study.

\section{Descriptive Statistics}

Our analysis focused on lower extremity pseudocellulitis patients with cellulitis as the primary diagnosis (Figure). Patient demographics, length of hospitalization, antibiotic usage, unnecessary admissions, and complications were reported as means (standard deviation [SD]) and counts (percent).

\section{Cost Calculations}

The cost analysis was based partially on data from previously published literature. PubMed and Google Scholar were searched for the previous decade (January 2005 to December 2015), using the following search terms: "cellulitis" or "skin and soft tissue infection" or "abscess," "emergency department," and "United States." References of key articles were manually searched to find additional articles. Articles were reviewed for primary data on the total annual cases of cellulitis presenting to the $\mathrm{ED}$, abscess rates, anatomical distribution, and rate of inpatient admission.

A total of 15 articles were selected with preference given for recent studies with larger cohorts that reported these values (eTable 1 in the Supplement). These variables, in addition to variables calculated from our study (rate of cellulitis misdiagnosis, proportion of misdiagnosed cellulitis cases in which cellulitis is the primary diagnosis, and rate of unnecessary admissions) were used to calculate the annual number of misdiagnosed lower extremity cellulitis cases resulting in unnecessary inpatient admission from the ED in the United States (eTables 2 and 3 in the Supplement). Cost ranges were centered around median values identified through our literature search. Abscess was excluded from our cost calculation and, owing to the highly variable abscess rate in the literature, we used a range of values provided.

We obtained national cost figures from the Medical Expenditure Panel Survey (MEPS), provided by the Agency for Healthcare Research and Quality (AHRQ) for $2010^{19}$ to calculate the hospitalization costs per year attributed to misdiagnosed lower extremity pseudocellulitis. We next determined the average length of hospitalization for pseudocellulitis patients in which presumed cellulitis was the primary reason for admission and admission was unnecessary. To calculate the hospital cost per patient, the average patient length of stay was multiplied by the per diem cost of an average inpatient stay of that length. This value was multiplied by the total annual cases of misdiagnosed lower extremity cellulitis as calculated above (eTable1 in the Supplement) to estimate the annual cost of misdiagnosed cellulitis in the United States.

\section{Results}

\section{Patient Characteristics}

A total of 840 patient encounters were identified, of which 259 met inclusion criteria (Figure). Of these included patients, 79

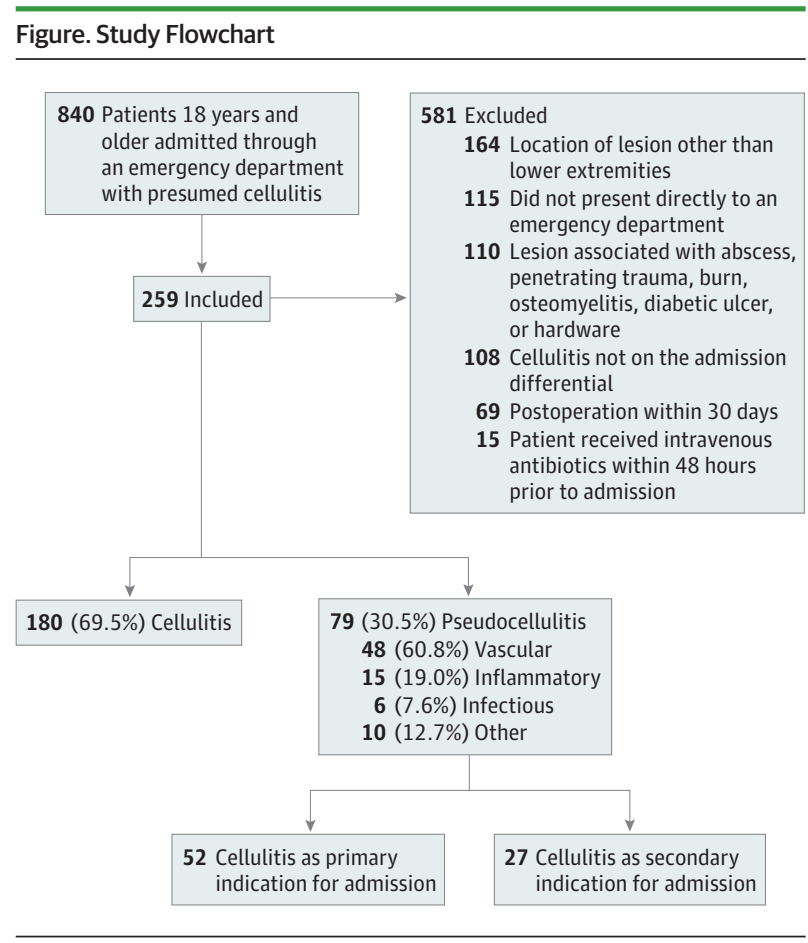

(30.5\%) patients were given an alternative diagnosis during the hospital course or within 30 days of discharge and were considered to have pseudocellulitis (Figure) (eTable 4 in the Supplement). The remaining 180 (69.5\%) were all discharged with a diagnosis of cellulitis. Fifty-two (65.8\%) of the patients with pseudocellulitis had cellulitis as the primary diagnosis on admission, and this subgroup was used for all subsequent analyses to determine the complications and costs attributable to the misdiagnosis of cellulitis. Within this subgroup, 50\% were female, the mean (SD) age was 60.4 (17.6) years, $71 \%$ were white, $14 \%$ were black, $8 \%$ were Hispanic, and $8 \%$ were other races (Table 1).

\section{Healthcare Utilization Secondary to Misdiagnosis}

Among the 52 pseudocellulitis patients admitted primarily for cellulitis, the mean (SD) length of hospitalization stay was 4.8 (4.0) days, with $25 \%$ staying longer than a week (Table 1). All 52 patients received at least 1 antibiotic intravenously while in the hospital, with 31 (60\%) receiving 2 or more. Thirty (58\%) of the 52 patients were discharged on antibiotics, with 28 (54\%) receiving oral antibiotics and $2(4 \%)$ receiving antibiotics intravenously.

Clinical review revealed that 44 (85\%) of 52 patients with misdiagnosed cellulitis would not have required hospital admission for treatment had they been diagnosed correctly (Table 1). The mean (SD) length of stay for these unnecessary admissions was 4.3 (3.7) days. Forty-eight (92\%) of the 52 patients would not have required any antibiotics based on their ultimate diagnoses. Furthermore, of the 30 pseudocellulitis patients who received antibiotics on discharge, 26 (87\%) did not require antibiotics at discharge based on their correct diagnoses.

We evaluated patients' utilization of health care within 30 days after discharge. Of note, 8 of 52 patients had no record 
Table 1. Characteristics, Health Care Utilization, and Complications of Pseudocellulitis Patients With Cellulitis as Primary Diagnosis

\begin{tabular}{|c|c|}
\hline Characteristic & $\begin{array}{l}\text { Pseudocellulitis } \\
\text { No. (\%) }\end{array}$ \\
\hline Age, mean (SD) & $60.4(18)$ \\
\hline Female & $26(50)$ \\
\hline \multicolumn{2}{|l|}{ Race } \\
\hline Non-Hispanic white & $37(71)$ \\
\hline Black & $7(13)$ \\
\hline Hispanic & $4(8)$ \\
\hline Other & $4(8)$ \\
\hline Days hospitalized, mean (SD) & $4.8(4)$ \\
\hline \multicolumn{2}{|l|}{ Days hospitalized } \\
\hline Same day discharge & $1(2)$ \\
\hline 1 & $6(11)$ \\
\hline 2 & $12(23)$ \\
\hline $3-4$ & $15(29)$ \\
\hline $5-7$ & $5(10)$ \\
\hline More than 1 week & $13(25)$ \\
\hline Received oral antibiotics in 48 hours prior to admission & $13(25)$ \\
\hline Received antibiotics in hospital & $52(100)$ \\
\hline \multicolumn{2}{|l|}{ Number of antibiotics in hospital } \\
\hline 1 & $21(40)$ \\
\hline 2 & $20(39)$ \\
\hline$\geq 3$ & $11(21)$ \\
\hline Received any antibiotics at discharge & $30(58)$ \\
\hline Received antibiotics intravenously at discharge & $2(4)$ \\
\hline Received oral antibiotics at discharge & $28(54)$ \\
\hline Unnecessary admission & $44(85)$ \\
\hline Days hospitalized, mean (SD) & $4.3(4)$ \\
\hline Unnecessary antibiotics in hospital & $48(92)$ \\
\hline Unnecessary antibiotics on discharge & $26(50)$ \\
\hline Complications within 30 days $^{a}$ & $14 / 44(32)$ \\
\hline \multicolumn{2}{|l|}{ Complication types $^{\mathrm{b}}$} \\
\hline Rash & $1 / 44(2)$ \\
\hline Gastrointestinal tract upset & $2 / 44(4)$ \\
\hline Diarrhea & $1 / 44(2)$ \\
\hline ED revisit & $4 / 44(9)$ \\
\hline Outpatient visit for complication & $3 / 44(7)$ \\
\hline Readmission & $6 / 44(14)$ \\
\hline
\end{tabular}

Abbreviation: ED, emergency department.

a For calculation of complications, 8 patients had no record available for 30-day comparison and were omitted; therefore the percentages reported are out of 44 patients.

${ }^{\mathrm{b}}$ No cases of anaphylaxis, Clostridium difficile infection, infusion reactions, peripherally inserted central catheter line placements or complications, or hematologic abnormalities were identified.

available for 30-day comparison and were omitted from our complication analysis; therefore these following percentages are calculated out of 44 included patients. Fourteen (31.8\%) patients had a complication or potentially avoidable utilization of health care related to their misdiagnosis, antibiotics, or hospital stay (Table 1). Three (6.8\%) patients had an outpatient visit for a complication and 6 (13.6\%) patients were readmitted within 30 days. Patient complications included drug eruption, diarrhea, and gastrointestinal distress.
Table 2. Economic Cost of Hospital Admission for Misdiagnosed Lower Extremity Cellulitis

\begin{tabular}{lccll}
\hline & \multicolumn{4}{l}{ Misdiagnosis Rate, $\$$} \\
\cline { 2 - 5 } Abscess Rate & $15 \%$ & $30 \%$ & $30.5 \%^{\mathrm{b}}$ & $45 \%$ \\
\hline Minimum $12.9 \%^{\mathrm{b}}$ & 253 & 506 & 515 & 760 \\
\hline Median $35 \%^{\mathrm{b}, 2,20-23}$ & 189 & 378 & 384 & 567 \\
\hline Maximum $67 \%^{2}$ & 96 & 192 & 195 & 288 \\
\hline
\end{tabular}

${ }^{a}$ Ranges of cellulitis misdiagnosis and abscess rates were used to calculate economic cost of hospitalization. Presented in \$ millions.

${ }^{\mathrm{b}}$ Rate per our current study.

\section{Economic Cost of Misdiagnosis}

Of the patients admitted for cellulitis through the ED, 30\% were ultimately found to have pseudocellulitis (Figure). Among patients misdiagnosed with cellulitis, 52 of 79 (66\%) were admitted primarily for inpatient treatment of cellulitis, and 44 of 52 (85\%) of these admitted patients did not require admission based on their ultimate diagnosis (Figure) (Table 1).

When determining the total number of patients who are admitted annually through the ED for uncomplicated lower extremity cellulitis, we excluded patients who presented with an abscess. In our current study we demonstrate an abscess rate of 108 of 840 (12.9\%), and found a range of $15 \%$ to $67 \%$,20-23 per our literature review. Therefore, we use a range from $12.9 \%$ to $67 \%$ for our calculations, and cellulitis cases complicated by abscess were removed from our cost calculations. Based on a median of 2590380 patients presenting to the ED with cellulitis annually, $1,6,20,24,25$ this results in an estimated 90000 to 240000 patients who are admitted annually through the ED for uncomplicated lower extremity cellulitis (see detailed calculations in eTable 2 in the Supplement).

According to the Household Component of the Medical Expenditure Panel Survey (MEPS-HC) for hospital inpatient stays in 2010, the cost for the mean length of hospital stay for unnecessary admissions (4.3 days) is $\$ 12656.90$ (Table 1 ). ${ }^{19}$ Based on these data and a review of the literature, we estimated that there are between 18000 and 48000 patients admitted through the ED with a primary diagnosis of presumed lower extremity cellulitis who are misdiagnosed, of which 15000 to 40000 are unnecessary (eTable 2 in the Supplement). This leads to 66000 to 175000 excess inpatient days at an annual cost of $\$ 195$ million to $\$ 515$ million (eTable 3 in the Supplement) (Table 2). This estimate does not include the additional cost of antibiotics after discharge or subsequent health care visits for complications related to unnecessary cellulitis treatment.

\section{Medical Complications of Misdiagnosis}

Current estimates show that for every 8 to 39 patients treated with antibiotics 1 will develop $C$ difficile colitis, ${ }^{26,27}$ and $0.004 \%$ to $0.015 \%$ of patients develop antibiotic-induced anaphylaxis. ${ }^{28,29}$ Furthermore, hospitalization carries the risk of nosocomial infections, with an average rate of $4 \%$ from the most recent Center for Disease Control (CDC) reports. ${ }^{30}$ While none of the patients in our cohort developed nosocomial infections, C difficile infection, or anaphylaxis, when extrapolated across the estimated 


\begin{tabular}{|c|c|c|c|c|}
\hline \multirow[b]{2}{*}{ Complication } & \multirow[b]{2}{*}{$\begin{array}{l}\text { Complication } \\
\text { Rates,a \% }\end{array}$} & \multicolumn{2}{|l|}{ Exposed Population } & \multirow[b]{2}{*}{$\begin{array}{l}\text { Estimated Patients } \\
\text { in the United States } \\
\text { Affected Annually, No. }\end{array}$} \\
\hline & & $\begin{array}{l}\text { Patients Exposed } \\
\text { to Unnecessary } \\
\text { Antibiotics }^{c}\end{array}$ & $\begin{array}{l}\text { Patients } \\
\text { Admitted } \\
\text { to Hospital }\end{array}$ & \\
\hline $\begin{array}{l}\text { Clostridium difficile } \\
\text { infection } 26,27\end{array}$ & $2.6-12.5$ & $16826-44409$ & NA & $437-5551$ \\
\hline Anaphylaxis ${ }^{28,29}$ & $0.004-0.015$ & $16826-44409$ & NA & $1-7$ \\
\hline $\begin{array}{l}\text { Nosocomial } \\
\text { infections }{ }^{30}\end{array}$ & 4.0 & NA & $15422-40705$ & $617-1628$ \\
\hline
\end{tabular}

\author{
Abbreviation: NA, not applicable for \\ calculation. \\ ${ }^{\text {a }}$ As reported in the literature. \\ ${ }^{b}$ Calculated by number of \\ patients $=$ complication rate $\times$ \\ exposed population. \\ c Per calculations in eTable 3 in the \\ Supplement.
}

population of all patients with misdiagnosed cellulitis, we estimate that inappropriate interventions result in 617 to 1628 nosocomial infections, 437 to 5551 cases of $C$ difficile colitis, and 1 to 7 cases of anaphylaxis annually (Table 3 ).

\section{Discussion}

In this study, we evaluate the clinical and economic consequences of lower extremity cellulitis misdiagnosis. Of 259 patients admitted with presumed cellulitis, 79 (30.5\%) were misdiagnosed with cellulitis. Of these misdiagnosed patients, 52 patients were admitted primarily for the treatment of cellulitis and further analysis showed that $44(84.6 \%)$ did not require hospital admission, and that 48 (92.3\%) received unnecessary antibiotics. Misdiagnosis of cellulitis results in \$195 million to 515 million annually in avoidable health care spending, exclusive of the costs of antibiotics and complications resulting from inappropriate treatment.

We estimate from our study that more than 44000 pseudocellulitis patients are exposed to unnecessary antibiotics annually in the United States, with a hospital readmission rate of $13 \%$ and complications such as rash and gastrointestinal distress. Antibiotic exposure and unnecessary hospitalization places patients at risk for $C$ difficile infection, anaphylaxis, gastrointestinal distress, dermatological complications, and nosocomial infections. Our study highlights potentially avoidable complications and opportunities to reduce significant morbidity and mortality from cellulitis misdiagnosis.

Our findings support and expand on prior studies that have demonstrated high cellulitis misdiagnosis rates. ${ }^{14,16}$ We add to existing data on the incidence of misdiagnosis with a characterization of the clinical and economic health care burden of misdiagnosed cellulitis. While our misdiagnosis rate falls within the lower bounds of the range reported in the literature, the value is most consistent with other large-scale studies focusing specifically on lower extremity cellulitis. ${ }^{14}$ Additionally, educating nondermatological specialties on pseudocellulitis and encouraging early dermatology consultation may contribute to lower misdiagnosis rates at our institution.

Misdiagnosis of cellulitis has considerable implications for antibiotic stewardship. Nearly a third of pseudocellulitis patients in our study experienced a complication as a direct result of unnecessary treatment for presumed cellulitis. Antibiotic use is associated with increased risk of antibiotic drug toxic effects, anaphylaxis, prolonged hospitalization, and selection of resistant microorganisms. ${ }^{31}$ While none of our pa- tients were diagnosed with $C$ difficile colitis or anaphylaxis, these complications carry the potential for considerable morbidity and mortality and should be a component of judicious evaluation of appropriate antibiotic use.

\section{Limitations}

Our findings must be interpreted in the context of the study design. This investigation was performed at a single institution, and although the patients span a wide range of age and racial demographics, additional studies are needed to assess the generalizability of our findings. Our patients were selected from those admitted from the ED for presumed cellulitis, and these results may not apply in other clinical settings. Decisions for admission may be influenced by nonmedical factors (eg, homelessness), which were not captured in our analysis.

Furthermore, we present ranges of potential costs and used conservative estimates that may underestimate the true costs of misdiagnosis; these estimates and ranges should be validated in a prospective multi-institutional study in multiple care settings to reduce variability. Rates of complications such as C difficile colitis and anaphylaxis were limited in our small cohort, and additional studies are needed to evaluate the spectrum of potentially avoidable complications resulting from unnecessary antibiotics.

Consistent with the established standard in cellulitis research, our study parameters allowed for the diagnosis of cellulitis to be made by specialties outside of dermatology, and therefore not all cases of pseudocellulitis may be captured. ${ }^{32,33}$ Although dermatologists have been shown to identify pseudocellulitis at a high rate, most patients with presumed cellulitis are never evaluated by a dermatologist, and this captures a range of clinical presentations more commonly seen in practice.

\section{Conclusions}

Our study serves as a call to arms for improving the care of patients with suspected lower extremity cellulitis. A combination of systems improvement and further categorization of the biology of cellulitis may lead to a combination of clinical findings and biomarkers that will reduce incorrect diagnosis. It has been previously shown that dermatology consultation in the inpatient setting may be helpful in increasing diagnostic accuracy, ${ }^{16,34}$ and we are presently in the process of developing a predictive model for the assessment of possible cellulitis. 


\section{ARTICLE INFORMATION}

Correction: This article was corrected online on December 7, 2016, to correct an error in the credentials of one of the authors in the byline. Where it previosly read Jean-Phillip Okhovat, BS, it now correctly reads Jean-Phillip Okhovat, MD, $\mathrm{MPH}$.

Accepted for Publication: August 16, 2016.

Published Online: November 2, 2016

doi:10.1001/jamadermatol.2016.3816

Author Contributions: Drs Raff and Wang contributed equally to the work and are considered co-first authors. Drs Raff and Mostaghimi had full access to all of the data in the study and take responsibility for the integrity of the data and the accuracy of the data analysis.

Study concept and design: Kroshinsky, Mostaghimi, Raff, Weng.

Acquisition, analysis, or interpretation of data: All authors.

Drafting of the manuscript: Cohen, Joyce,

Mostaghimi, Raff, Weng.

Critical revision of the manuscript for important intellectual content: All authors.

Statistical analysis: Joyce, Mostaghimi, Raff, Weng. Administrative, technical, or material support: Kroshinsky, Mostaghimi, Okhovat.

Study supervision: Kroshinsky, Mostaghimi, Raff.

Conflict of Interest Disclosures: None reported.

\section{REFERENCES}

1. Khachatryan A, Patel D, Stephens J, Johnson K, Patel A, Talan D. Skin and skin structure infections (SSSIs) int he emergency department (ED): Who gets admitted? http://content.stockpr.com /duratatherapeutics/db/Publications/2774/file /5-6e_SAEM_Poster.pdf. Accessed October 4, 2016 2. Talan DA, Salhi BA, Moran GJ, et al. Factors associated with decision to hospitalize emergency department patients with skin and soft tissue infection. West J Emerg Med. 2015;16(1):89-97.

3. Venkatesh AK, Dai Y, Ross JS, Schuur JD, Capp R Krumholz HM. Variation in US hospital emergency department admission rates by clinical condition. Med Care. 2015;53(3):237-244.

4. Christensen KL, Holman RC, Steiner CA, Sejvar JJ, Stoll BJ, Schonberger LB. Infectious disease hospitalizations in the United States. Clin Infect Dis. 2009:49(7):1025-1035.

5. The DRG Handbook. Comparative Clinical and Financial Benchmarks. Evanston, IL: Solucient; 2006. 6. Hersh AL, Chambers HF, Maselli JH, Gonzales R. National trends in ambulatory visits and antibiotic prescribing for skin and soft-tissue infections. Arch Intern Med. 2008;168(14):1585-1591.

7. Healthcare Cost and Utilization Project (HCUP) Nationwide Inpatient Sample (NIS) Most Frequent
Conditions in US Hospitals, 2011. http://www.hcup -us.ahrq.gov/nisoverview.jsp. Accessed November 2, 2014.

8. Koutkia P, Mylonakis E, Boyce J. Cellulitis: evaluation of possible predisposing factors in hospitalized patients. Diagn Microbiol Infect Dis. 1999:34(4):325-327.

9. Krasagakis $K$, Valachis $A$, Maniatakis $P$, Krüger-Krasagakis S, Samonis G, Tosca AD. Analysis of epidemiology, clinical features and management of erysipelas. Int J Dermatol. 2010;49(9):1012-1017.

10. Hirschmann JV, Raugi GJ. Lower limb cellulitis and its mimics: part I. Lower limb cellulitis. J Am Acad Dermatol. 2012;67(2):163.e1-163.e12.

11. Dupuy A, Benchikhi H, Roujeau JC, et al. Risk factors for erysipelas of the leg (cellulitis): case-control study. BMJ. 1999;318(7198):1591-1594.

12. Gunderson CG, Martinello RA. A systematic review of bacteremias in cellulitis and erysipelas. J Infect. 2012;64(2):148-155.

13. Chira S, Miller LG. Staphylococcus aureus is the most common identified cause of cellulitis: a systematic review. Epidemiol Infect. 2010;138(3): 313-317.

14. Levell NJ, Wingfield CG, Garioch JJ. Severe lower limb cellulitis is best diagnosed by dermatologists and managed with shared care between primary and secondary care. $\mathrm{Br} J$ Dermatol. 2011;164(6):1326-1328.

15. David CV, Chira S, Eells SJ, et al. Diagnostic accuracy in patients admitted to hospitals with cellulitis. Dermatol Online J. 2011:17(3):1.

16. Arakaki RY, Strazzula L, Woo E, Kroshinsky D. The impact of dermatology consultation on diagnostic accuracy and antibiotic use among patients with suspected cellulitis seen at outpatient internal medicine offices: a randomized clinical trial. JAMA Dermatol. 2014;150(10):1056-1061.

17. Kroshinsky D, Grossman ME, Fox LP. Approach to the patient with presumed cellulitis. Semin Cutan Med Surg. 2007;26(3):168-178.

18. Harris PA, Taylor R, Thielke R, Payne J, Gonzalez $\mathrm{N}$, Conde JG. Research electronic data capture (REDCap)-a metadata-driven methodology and workflow process for providing translational research informatics support. J Biomed Inform. 2009:42(2):377-381.

19. Mirel L, Carper K. Expenses for Hospital Inpatient Stays, 2010. Agency for Healthcare Research and Quality. Statistical Brief \#401. http: //meps.ahrq.gov/mepsweb/data_files/publications /st401/stat401.pdf. Accessed February 10, 2016

20. Prusakowski MK, KuehI DR. Trends in emergency department management of skin abscesses. Am J Infect Control. 2015;43(4):336-340.

21. Merritt C, Haran JP, Mintzer J, Stricker J, Merchant RC. All purulence is local - epidemiology and management of skin and soft tissue infections in three urban emergency departments. BMC Emerg Med. 2013;13:26.

22. Jeng A, Beheshti M, Li J, Nathan R. The role of beta-hemolytic streptococci in causing diffuse, nonculturable cellulitis: a prospective investigation. Medicine (Baltimore). 2010;89(4):217-226.

23. Schrock JW, Laskey S, Cydulka RK. Predicting observation unit treatment failures in patients with skin and soft tissue infections. Int J Emerg Med. 2008:1(2):85-90.

24. Pallin DJ, Egan DJ, Pelletier AJ, Espinola JA, Hooper DC, Camargo CA Jr. Increased US emergency department visits for skin and soft tissue infections, and changes in antibiotic choices, during the emergence of community-associated methicillin-resistant Staphylococcus aureus. Ann Emerg Med. 2008;51(3):291-298.

25. Mistry RD, Shapiro DJ, Goyal MK, et al. Clinical management of skin and soft tissue infections in the U.S. Emergency Departments. West J Emerg Med. 2014;15(4):491-498.

26. Fashner J, Garcia M, Ribble L, Crowell K. Clinical inquiry: what risk factors contribute to $C$ difficile diarrhea? J Fam Pract. 2011;60(9):545-547.

27. Thomas C, Stevenson M, Riley TV. Antibiotics and hospital-acquired Clostridium difficile-associated diarrhoea: a systematic review. J Antimicrob Chemother. 2003;51(6):1339-1350.

28. Weiss ME, Adkinson NF. Immediate hypersensitivity reactions to penicillin and related antibiotics. Clin Allergy. 1988;18(6):515-540.

29. Bochner BS, Lichtenstein LM. Anaphylaxis. N Engl J Med. 1991;324(25):1785-1790.

30. Magill SS, Edwards JR, Bamberg W, et al; Emerging Infections Program HealthcareAssociated Infections and Antimicrobial Use Prevalence Survey Team. Multistate point-prevalence survey of health care-associated infections. N Engl J Med. 2014;370(13):1198-1208.

31. Çakmakçi M. Antibiotic stewardship programmes and the surgeon's role. J Hosp Infect. 2015;89(4):264-266.

32. Björnsdóttir S, Gottfredsson M, Thórisdóttir AS et al. Risk factors for acute cellulitis of the lower limb: a prospective case-control study. Clin Infect Dis. 2005:41(10):1416-1422.

33. McNamara DR, Tleyjeh IM, Berbari EF, et al. A predictive model of recurrent lower extremity cellulitis in a population-based cohort. Arch Intern Med. 2007;167(7):709-715.

34. Strazzula L, Cotliar J, Fox LP, et al. Inpatient dermatology consultation aids diagnosis of cellulitis among hospitalized patients: a multi-institutional analysis. J Am Acad Dermatol. 2015;73(1):70-75. 